\title{
MODEL DAKWAH PENDIDIKAN SEKS \\ (Studi Kasus Perkumpulan Keluarga Berencana Indonesia DKI Jakarta)
}

\author{
Resta Ayuning Putri,* Dewi Anggraeni, dan Zulkifli Lubis \\ Universitas Negeri Jakarta \\ *E-mail: restaayuning力_iai13@mahasiswa.unj.ac.id
}

\begin{abstract}
The research as a purpose for describe sex education of da'wah model, sex education important for child to procure true information about sex problem. The purpose of this research is to find and describe of sex education of da'wah conducted by PKBI DKI. The method used in this research is descriptive qualitative method wich researchers do research by observation and interview. From the data of researchers, the research describe the data have been self language. The study uses the theory obtain using sex education an theory of da'wah. From the theory will be connected with the result of research from the result of research. From the results of this study obtained that PKBI DKI is social institutions that have the goal or mission of da'wah in sex education from materi, method, and media da'wah. The materi presented by PKBI DKI is adjusted to the age of the child and the need for sex education for child. So also with the media used.
\end{abstract}

Keywords: Sex Education, Da'wah, Material Da'wah, Media Da'wah

\begin{abstract}
ABSTRAK
Penelitian ini berbicara tentang model dakwah pendidikan seks, pendidikan seks adalah penting bagi anak untuk memperoleh informasi yang benar tentang masalah seksual. Tujuan penelitian ini adalah untuk mengetabui dan mendeskripsikan gambaran model dakwah pendidikan seks yang dilakukan oleh Perkumpulan Keluarga Berencana Indonesia (PKBI) DKI Jakarta. Metode yang digunakan dalam penelitian ini adalah metode kualitatif deskriptif, yang dimana peneliti melakukan penelitian dengan observasi dan wawancara. Dari data hasil penelitian tersebut peneliti mendeskripsikan data yang telah didapat menggunakan bahasa peneliti sendiri. Penelitian ini menggunakan teori pendidikan seks dan teori dakwah. Dari hasil penelitian tersebut diperoleb babwa PKBI DKI Jakarta adalah lembaga sosial yang memiliki tujuan atau misi dakwah dalam pendidikan seks. Mulai dari materi, metode, dan media pendidikan seks yang digunakan banyak yang sesuai dengan materi, metode, dan media dakwah. Materi yang disampaikan oleh PKBI DKI disesuaikan dengan usia anak. dan kebutuban pendidikan seks bagi anak. Begitu juga dengan media yang digunakan.
\end{abstract}

Kata Kunci: Dakwah, Materi Dakwah, Media Dakwah, Pendidikan Seks.

TARBAWY: Indonesian Journal of Islamic Education - Vol. 4 No. 2 (2017) | 151 


\section{PENDAHULUAN}

Pendidikan seks sebenarnya berarti pendidikan mengenai seksualitas dalam arti luas. Seksualitas meliputi berbagai aspek yang berkaitan dengan seks, yaitu aspek biologic, orientasi, nilai sosiokultur dan moral, serta perilaku. Sesuai dengan kelompok usia berdasarkan perkembangan hidup manusia, maka pendidikan seks dapat dibagi menjadi pendidikan seks prasekolah, dan sekolah, pendidikan seks untuk remaja, pendidikan seks untuk dewasa pranikah serta menikah (Madani, t.t., hlm. 16). Sudah bukan saatnya lagi mengindetifikasi pendidian seks sebagai sesuatu yang tabu. Pendidikan ini penting sebagai usaha preventif agar remaja bisa mengidentifikasi pelecehan dan kekerasan seksual. Remaja berhak untuk tahu haknya, sehingga bisa mengetahui konsekuensi atas pilihan-pilihan yang dibuatnya. Terlebih lagi, Indonesia sudah meratifikasi CEDAW (Konvensi tentang penghapussan segala bentuk diskriminasi terhadap perempuan) dalam UU No. 7 tahun 1984, Konvensi Hak Anak dalam UU No. 22 tahun 2002, serta HAM dalam UU No. 39 tahun 1999.

Sedikit sekali masyarakat terutama orang tua yang peduli akan pendidikan seks dan menempatkan seks adalah sesuatu yang penting. Bahkan banyak orang tua yang tidak memberikan pendidikan seks pada anak, dengan alasan anak akan tahu dengan sendirinya. Selama ini seks identik dengan orang dewasa saja (Andriana, 2006, hlm. 86). Gambaran mengenai banyaknya seks bebas maupun seks di bawah umur diduga antara lain karena mereka kurang memahami perilaku seks yang sehat. Pendidikan seks sangat dibutuhkan untuk anak-anak, karena dengan adanya pendidikan seks anak-anak dapat belajar tentang seks dengan benar dan sesuai dengan keimuan yang ada. Anak-anak tidak belajar sendiri dan mencari tau informasi tentang seks diinternet tanpa pengawasan dari orang tua ataupun guru (Martin, 1998, hlm. 9).

Pendidikan seks tidak hanya harus diajarkan di sekolah, tetapi peran masyarakat dan dakwah juga berpengaruh dalam memberi pengetahuan pendidikan seks kepada anak (Andriana, 2006, hlm. 56). Dakwah termasuk cara yang efesien untuk mengajarkan anak tentang pendidikan seks, dakwah pendidikan seks tidak harus dilakukan di masjid dengan jumlah mad'u yang banyak. Tetapi dakwah pendidikan seks ini sangat efesian jika dilakukan dengan cara komunikasi interpersonal antara anak dan da'i. Karena dengan begitu anak akan lebih mengerti dan paham apa yang diajarkan oleh da'i.

Menyikapi berbagai masalah di atas terkait pendidikan seks, sampel dakwah yang diambil adalah PKBI, sejauh mana peran PKBI dalam mendakwahkan pendidikan seks kepada para remaja. Di mana PKBI mempunyai andil yang sangat signifikan dalam pendidian seks usia dini kepada para remaja, hal tersebut dapat dilihat dari perannya sebagai lembaga yang rutin melakukan sosialisasi kepada anak-anak Sekolah Dasar hingga Sekolah Menengah. 
Tidak hanya mensosialisasikan tentang pendidikan seks kepada anak, PKBI juga memfasilitasi anak-anak untuk mengaplikasikan pengetahuan mereka tentang pendidikan seks yang sudah diajarkan oleh PKBI.

Pendidikan seks adalah upaya pengajaran, penyadaran, dan pemberian informasi tentang masalah seksual. Informasi yang diberikan diantaranya adalah pengetahuan tentang fungsi organ, reproduksi dengan menanamkan moral, etika, komitmen, dan agama, agar tidak terjadi penyalahgunaan organ reproduksi tersebut. Karena itu pendidikan seks dapat dikatakan sebagai cikal bakal pendidikan kehidupan berkeluarga yang memiliki makna sangat penting. Para ahli psikologi menganjurkan agar pendidikan seks mulai dikenalkan pada anak sejak usia dini, sesuai dengan tahap perkembangan kedewasaannya (Hana, 2009, hlm. 10).

Andika menyatakan bahwa "pendidikan seks bertujuan untuk memperkenalkan anak tentang jenis kelamin dan cara menjaganya, baik dari sisi kesehatan dan kebersihan, keamanan serta keselamatan". Sedangkan menurut Kir Kendall (dalam Ulwan, 1996, hlm. 214-217) bahwa tujuan pendidikan seks adalah:

a. Membentuk pengertian dalam perbedaan seks antara pria dan wanita dalam keluarga, pekerjaan dalam seluruh kehidupan yang selalu berbubah dan berbeda dalam tiap masyarakat dan kebudayaan. b. Membentuk pengertian tentang peranan seks didalam kehidupan manusia dan keluarga.

c. Mengembangkan pengertian diri sendiri sehubungan dengan fungsi dan kebutuhan seks.

d. Membantu murid dalam mengembangkan kepribadiannya sehingga mampu untuk mengambil keputusan yang bertanggung jawab, misalnya, memilih jodoh, hidup berkeluarga, dan kesusilaan dalam seks, dll.

Definisi mengenai dakwah, telah banyak dibuat para ahli, dimana masing-masing definisi tersebut saling melengkapi. Walaupun berbeda susunan redaksinya, namun maksud dan makna hakikinya sama. Esensi dakwah adalah mengajak manusia dengan cara bijaksana kepada jalan yang benar sesuai dengan perintah Tuhan, untuk keselamatan dan kebahagiaan mereka didunia dan akhirat (Aceh, 1986, hlm. 11).

Untuk mencapai keberhasilan dakwah Islam secara maksimal, maka diperlukan berbagai factor penunjang, diantaranya adalah strategi dakwah yang tepat sehingga dakwah Islam mengenai sasaran. Strategi yang digunakan dalam usaha dakwah haruslah memperhatikan beberapa asas dakwah, yaitu asas filosofi, asas kemampuan dan keahlian da'i, asas sosiologis, asas psikologis, asas efektivitas dan efesiensi (Amin, 2009, hlm. 107-108).

\section{METODE PENELITIAN}

Penelitian ini merupakan penelitian kualitatif yaitu penelitian 
lapangan dengan mengumpulkan informasi atau data tentang keadaankeadaan secara nyata dari orang-orang dan perilaku yang diamati kemudian dikumpulkan dan dinyatakan dalam bentuk kata-kata dan gambar.

\section{Tempat dan Waktu Penelitian \\ Dalam penelitian kualitatif tidak} dikenal istilah populasi dan sampel. Istilah yang digunakan adalah setting atau tempat penelitian. Tempat penelitiannya adalah Kantor Perkumpulan Keluarga Berencana DKI Jakarta. Peneliti mendeskripsikan setiap informasi dan kejadian yang terjadi dilapangan seperti respon anak dan kegiatan pendidikan seks pada saat peneliti melakukan observasi. Peneliti melakukan penelitian selama empat bulan (Februari-Maret 2017).

\section{Teknik Pengumpulan Data}

Teknik pengumpulan data yang digunakan dalam penelitian ini yaitu observasi, wawancara dan dokumentasi. Peneliti menggunakan tiga tahapan dalam proses analisis data yaitu mendeskripsikan, menganalisis dan menginterpretasikan hasil penelitian yang sudah dilakukan di Kantor PKBI DKI dan Sekolah yang bekerjasama dengan PKBI DKI.

\section{HASIL PENELITIAN DAN PEMBAHASAN}

Dari hasil penelitian yang telah peneliti lakukan, peneliti dapat mengetahui dan mendekripsikan model dakwah pendidikan seks yang dilakukan oleh PKBI DKI. Mereka menggunakan model dakwah yang tepat, dilihat dari materi dan media yang dipakai sesuai dengan kurikulum pendidikan seks yang ada. Berikut adalah rincian hasil penelitian tersebut.

\section{Peran PKBI DKI Jakarta dalam Pendidikan Seks}

PKBI mengembangkan program remaja sejak tahun 1970-an. Sampai saat ini sudah sebagai bentuk dan model program remaja yang telah dikembangkan. Keluarga Berencana dan Kependudukan (1970-1980) Biduk Kencana, Biduk Wiraja, RSB. Program remaja yang dikembangkan pada masa ini lebih ditekankan pada pengenalan remaja tentang pentingnya perencanaan keluarga (KB) mencakup usia nikah ideal, pengaturan kelahiran, serta meningkatkan kepedulian remaja terhadap masalah kependudukan. Pada saat itu masyarakat masih belum bisa menerima KB secara terbuka. Peran PKBI lebih mempersiapkan secara sosial akan penerimaan program KB untuk kepentingan kesehatan ibu dan anak serta untuk kepentingan penurunan laju pertumbuhan penduduk.

Centra Mitra Muda (CMM) adalah youth centre PKBI DKI Jakarta yang berperan sebagai pusat informasi dan pelayanan kesehatan reproduksi remaja. Karena fungsinya tersebut, Sejak didirikan pada tahun 1992, CMM memiliki perhatian khusus terhadap isu-isu remaja, terutama yang terkait dengan masalah kesehatan reproduksi serta HIV dan AIDS. CMM dalam melaksanakan kegiatan sudah tidak berpusat di dalam sekretariat CMM saja (in center base), tetapi juga sudah melaksanakan 
kegiatan di luar sekretariat CMM (out center) dan dilakukan dengan seimbang.

Walaupun PKBI DKI Jakarta bukan lembaga sosial pemerintahan tetapi PKBI DKI Jakarta tetap mengikuti peraturan perundangundangan yang ditatapkan oleh KEMENDIKBUD terkait pendidikan seks yang PKBI DKI berikan kepada anak-anak. Begitu juga dengan peraturan kepemerintahan sekitar mulai dari Peraturan Gubernur sampai Kecamatan dan Kelurahan yang bersangkutan. Menurut Heni Mulyati, memang sudah banyak peran PKBI DKI di masyarakat dalam pendidikan seks usia dini. Sejak PKBI DKI terbentuk hingga saat ini, mulai dari sekolah-sekolah sampai lingkungan sekitar kantor-kantor cabang PKBI DKI yang bekerjasama dengan karang taruna sekitar.

Sedangkan menurut Ela Jasmine, peran PKBI DKI memang sudah banyak sekali namun dari sisi agama dan dakwah memang belum maksimal karena mungkin masih sedikit fasilitator yang ahli dalam bidang agama dan dakwah ditambah lagi masih sedikit sekolah-sekolah islam yang mengajak kerjasama PKBI DKI dalam sosialisasi pendidikan seks usia dini. Menurut Alam, hal itu dikarenakan lingkungan Jombang dan Pamakasan yang banyak pesantren dan sekolah-sekolah Islam jadi wajar saja PKBI disana berbeda dengan PBKI DKI. PKBI Jombang dan PKBI Pamakasan memang dibentuk dengan background agama yang lebih daripada PKBI yang lainnya. Karena lingkungan di DKI juga yang bermacam-macam agama, ras, dan suku. Walaupun seperti itu jika PKBI DKI diajak kerjasama dengan pesantren atau sekolah Islam PKBI DKI tetap siap, dari segi fasilitator, materi, dll. PKBI DKI juga kadang bekerjasama dengan Guru PAI disekolah tersebut agar jika ada kesalahan materi yang disampaikan fasilitator bisa dikoreksi oleh Guru PAI yang memang ahli di bidangnya.

Dari beberapa pendapat diatas peneliti dapat menyimpulkan bahwa peran PKBI DKI Jakarta sangatlah penting di masyarakat. Terlebih lagi orang tua yang masih bingung atau segan mengajarkan anaknya tentang pendidikan seks usia dini, karena kebanyak orang tua berfikir kalau mengajarkan anak tentang seks itu terlalu dini dan belum waktunya anak mengerti tentang seks. Justru fikiran orang tua tersebut sangat keliru. Oleh karena itu banyak sekolah-sekolah yang bekerja sama dengan PKBI DKI Jakarta dalam mensosialisasikan pendidikan seks usia dini kepada anak. Pendidikan seks tidak hanya untuk anak tetapi PKBI DKI Jakarta juga memfasilitasi orang tua untuk belajar pendidikan seks, karena pendidikan seks itu sangat penting bagi masa depan anak. Supaya anak tidak mencari tahu sendiri perihal seks karena orang tua tidak mengajarinya. Sekarang ini banyak anak yang salah belajar tentang seks, mereka belajar dari internet bahkan tahu istilah-istilah seks dari teman sebayanya yang belum tentu benar.

\section{Materi Dakwah Pendidikan Seks \\ Materi yang diberikan oleh CMM PKBI DKI Jakarta sangat}


beragam, mulai dari aspek kesehatan, psikologi, sosial, keagamaan, tumbuh kembang, alat reproduksi dan masih banyak lagi. Namun, dalam penelitian ini peneliti lebih fokus kepada materi kesehatan alat reproduksi, tumbuh kembang anak. Karena materi tersebut yang sering disampaikan oleh PKBI DKI kepada anak-anak usia dini. Adapun materi-materi yang disampaikan oleh PKBI DKI terkait pendidikan seks usia dini adalah:

a. Tumbuh Kembang Remaja

b. Organ Reproduksi

c. Kesehatan Reproduksi

d. Mandi Junub atau Mandi Wajib

e. Perilaku Seksual

Menurut Ida, PKBI memiliki beberapa cara atau metode untuk menyampaikan pendidikan seks kepada anak. Tidak semua program PKBI dilakukan dengan cara seperti seminar ataupun penyuluhan. Tetapi ada pula yang dengan cara diskusi atau pun dengan cara sekedar ngobrol atau curhat. Biasanya hal-hal seperti ini terjadi kepada remaja yang sudah terlanjur terjerumus kedalam pergaulan bebas dan seks bebas. Setelah si anak curhat fasilitator memberikan masukan dan nasihatnasihat yang dapat membuat anak tersebut tidak putus asa dan menjadi lebih baik. Pendapat Ida tersebut juga sejalan dengan pendapat Ali Musthafa Yakub bahwa strategi pendekatan dakwah yang dilakukan oleh Nabi Muhammad Saw., adalah pendekatan personal, pendekatan pendidikan, pendekatan penawaran, pendekatan missi, pendekatan korespondensi, dan pendekatan diskusi.
Dari pendapat diatas dapat disimpulkan bahwa PKBI DKI telah melakukan sosialisasi dengan materi dakwah yang sesuai dengan syariat islam, namun tidak semuanya tapi didukung dengan aspek-aspek lainnya. Selain materi dakwah, PKBI DKI juga menggunakan metode penyampaian pendidikan seks yang biasa dipakai da'i untuk berdakwah. Dan juga beberapa strategi yang dilakukan PKBI DKI sama dengan strategi dakwah yang dilakukan oleh Nabi Muhammad saw. yaitu pendekatan personal, pendekatan pendidikan, dan pendekatan diskusi. Dan juga materi dakwah pendidikan seks ini diberikan sesuai umur dan kebutuhan anak, agar anak mengerti apa yang disampaikan oleh fasilitator. Dalam beberapa materi fasilitator juga menyelipkan tentang perintah Allah dalam larangan berzina, yang terdapat pada Q.S. Al-Isra' ayat 32 dan Q.S. An-Nur ayat 2. Dan dari beberapa hasil wawancara peneliti, menurut informan PKBI ini memiliki misi dakwah melalui pendidikan seks ini. Karena tujuan utama PKBI DKI adalah selain memberikan pendidikan seks kepada anak yaitu mengajak anak - anak untuk menjauhi seks bebas dan melarangnya untuk melakukan perilaku seks yang tidak sesuai syariat Islam.

\section{Media Dakwah Pendidikan Seks}

Setiap kegiatan belajar mengajar pasti menggunakan media, dengan tujuan agar anak yang diberikan pembelajaran mudah memahami dan akan terus mengingat apa yang dipelajari. Hal tersebut juga yang

TARBAWY: Indonesian Journal of Islamic Education - Vol. 4 No. 2 (2017) | 156 
dilakukan oleh PKBI DKI, menurut Ela Jasmine PKBI DKI selalu menggunakan media dalam sosialisasi pendidikian seks kepada anak. Tujuannya agar anak tidak mudah bosan saat fasilitator memberikan materi, karena biasanya untuk umuran anak dibawah 12 tahun itu mudah bosan dan fokusnya akan hilang jika dia melihat sesuatu yang monoton atau tidak menarik. Karena itulah media sangat penting dalam pendidikan seks ini, biasanya tiap sekolah atau perkumpulan remaja yang kita datangi beda-beda medianya, tergantung usia si anak dan keadaan lingkungan sekolah atau lingkungan rumah si anak.

Hal tersebut juga yang dilakukan oleh PKBI DKI, menurut Ela Jasmine PKBI DKI selalu menggunakan media dalam sosialisasi pendidikian seks kepada anak. Tujuannya agar anak tidak mudah bosan saat fasilitator memberikan materi, karena biasanya untuk umuran anak dibawah 12 tahun itu mudah bosan dan fokusnya akan hilang jika dia melihat sesuatu yang monoton atau tidak menarik. Karena itulah media sangat penting dalam pendidikan seks ini, biasanya tiap sekolah atau perkumpulan remaja yang kita datangi beda-beda medianya, tergantung usia si anak dan keadaan lingkungan sekolah atau lingkungan rumah si anak.

Tidak semua media digunakan dalam sosialisasi pendidikan seks. Semua itu tergantung jenis pesertanya. Misalnya, anak SD dari siswa SD itu juga dikualifikasikan lagi dari kelas berapa, rata-rata umur mereka berapa, dari situ dapat ditentukan media apa yang pas dan cocok untuk digunakan. Tidak mungkin kita sosialisasi ke remaja tetapi pakai media film animasi misalnya, yang terjadi remaja itu tidak tertarik dengan apa yang dijelaskan fasilitator terkait pendidikan seks.

Dari hasil penelitian yang peneliti dapatkan memang banyak media yang digunakan oleh PKBI DKI dalam memberikan pengetahuan tentang pendidikan seks kepada anak. Berikut adalah media-media yang digunakan oleh PKBI DKI Jakarta.
a. PowerPoint
b. Buku Cerita Bergambar
c. Kertas Body Mapping
d. Film Animasi
e. Puzzle
f. Poster
g. Alat Peraga

Menurut Heni Mulyati, PKBI DKI juga akan memberikan pembekalan tentang pembinaan keluarga sakinah. Namun, itu rencana program kerja baru. Tujuan program ini adalah memberikan pengetahuan pranikah khususnya bagi yang ingin nikah muda. Sebagai pembekalan untuk kehidupan berumah tangganya.

Dari beberapa media pendidikan seks diatas peneliti dapat menyimpulkan bahwa beberapa media yang dipakai oleh PKBI DKI Jakarta sama dengan teori media dakwah yang terdapat di kajian teori. Namun, menurut peneliti media yang digunakan oleh PKBI DKI masih kurang fariatif, karena seperti media boneka dan film animasi hanya digunakan pada saat-saat tertentu saja. Media yang digunkan oleh PKBI DKI 
telah mencakup unsur-unsur media dakwah yang dikemukakan oleh Darwanto Sastro Subroto dalam bukunya yang berjudul "Televisi Sebagai Media Pendidikan”.

\section{Metode Pendidikan Seks}

Banyak macam metode yang digunakan PKBI DKI dalam sosialisasi pendidikan seks usia dini. Metode itu digunakan sesuai dengan siapa yang menjadi peserta dalam sosialisasi pendidikan seks tersebut. PKBI DKI juga menyaring dan menklasifikasikan kriteria peserta, metode, dan juga media. Berikut adalah metode-metode yang digunakan PKBI DKI dalam sosialisasi pendidikan seks usia dini.

\section{a. Forum Group Discussion (FGD)}

Metode ini biasanya digunakan untuk anak-anak dibawah usia 11 tahun. Dalam satu ruangan dibagi menjadi 2 sampai 3 kelompok yang masing-masing kelompok terdapat satu orang fasilitator dari tim CMM PKBI DKI. Fasilitator akan menjelaskan tentang pendidikan seks dengan cara diskusi dan menggunakan media pembelajaran. Karena pesertanya rata-rata masih dibawah umur, dalam FGD tim CMM juga menggunakan media pretest dan postest.

\section{b. Seminar}

Biasanya metode seminar dilakukan untuk anak berusia $11-18$ tahun. Media yang biasa digunakan adalah power point, namun sesekali PKBI DKI juga menayangkan film tentang pendidikan seks agar anak tidak bosan. Dalam metode seminar juga sesekali diadakan pre test dan post test, tergantung kesediaan sekolah dan dilihat dari factor peseta, apakah peserta membutuhkan metode pre test atau tidak.

\section{c. Ceramah}

Metode ini seringkali digunakan di Pesantren atau ketika sekolah tersebut mengadakan acara keislaman. Namun untuk saat ini metode ini sudah jarang diapakai di PKBI DKI karena PKBI DKI juga sudah jarang bekerja sama dengan pesantren dalam sosialisasi pendidikan seks. Tetapi diluar PKBI DKI, seperti PKBI Jombang dan PKBI Pamakasan metode ceramah ini masih sering digunakan.

Dari pemaparan metode pendidikan seks usia dini yang dilakukan oleh PKBI DKI peneliti dapat disimpulkan bahwa PKBI DKI menggunakan tiga macam metode yaitu Forum Group Discussion (FGD), Seminar, dan Ceramah. Dari masing-masing metode ini digunakan sesuai klasifikasi peserta, mulai dari usia peserta, pengetahuan peserta terkait pendidikan seks, kebutuhan peserta dalam pendidikan seks. Dengan demikian media yang digunakan juga berbeda, media yang digunakan disesuaikan dengan metode dan kualifikasi peserta tersebut. Tidak hanya untuk siswa, metode ini juga digunakan untuk penjelasan terkait pendidikan seks kepada orang tua 
siswa disekolah tersebut, dengan tujuan orang tua mengetahui perkembangan dan pengetahuan anaknya terkait seks khususnya bagi siswa yang sudah memasuki usia remaja.

\section{Karakteristik Da'i}

Karakteristik untuk fasilitator anak usia dini atau sekitar 4 tahun sampai 11 tahun adalah mahasiswa dari berbagai jurusan, dapat berkomunikasi dengan baik, memahami pendidikan seks minimal dua aspek keilmuan. Untuk fasilitator ini biasanya PKBI DKI memberi pembekalan terhadap fasilitator terkait pendidikan seks, komunikasi, dll. Pembekalan pendidikan seks diberikan dari beberapa aspek, misal pendidikan seks dalam kajian Islam, pendidikan seks dalam norma kewarganegaraan, pendidikan seks dalam kesehatan, dll. Ini bertujuan agar si fasilitator paham tentang pendidikan seks dan tidak salah saat mensosialisasikan pendidikan seks kepada anak. Berbeda dengan fasilitator untuk remaja, walaupun karakteristiknya juga umum tetapi fasilitator yang dibutuhkan adalah yang sudah berpengalaman terhadap pendidikan seks, misal paham tentang HIV dan AIDS, paham tentang ayat quran atau hadist terkait seks atau pendidikan seks, dan lainlain.

\section{Respon Anak ketika Diberikan Pendidikan Seks}

Menurut Heni Mulyati, respon yang diperlihatkan anak-anak tersebut adalah contoh dari keadaan lingkungan sekitar mereka. Jadi sebenarnya tanpa kita sadari perilaku seks memang dekat dengan kehidupan sehari-hari. Ketika ditanya apa itu seks beberapa anak menjawab seks itu ciuman, pacaran, berduaan cowok sama cewek. Ketika ditanya lagi apakah mereka tau semua itu karena diajarkan orang tua dan rata-rata dari mereka menjawab tidak, dan menjelaskan kalau mereka diberi tahu oleh teman-temannya.

Selain itu, meurut Alam respon anak tergantung umur mereka. Karena di PKBI DKI sasaran pesertanya adalah siswa sekolah dasar sampai siswa sekolah menengah. Kalau untuk anak sekolah dasar yang berumur 5 sampai 11 tahun mereka akan menjawab pertanyaan yang diberikan oleh fasilitator sesuai apa yang mereka lihat, terkadang beda dengan siswa sekolah menengah kadang mereka menjawab pertanyaan ragu dan malu. Tidak sesuai dengan yang mereka alami.

Ketika ditanya "Apakah orang tua kalian pernah mengajarkan kalian tentang seks" kebanyakan dari anakanak tersebut menjawab "Tidak Pernah". Dari respon anak-anak diatas terkait pendidikan seks peneliti dapat menyimpulkan bahwa banyak anakanak yang mengetahui seks dengan sendirinya tidak ada bimbingan dari orang tua, sekolah, maupun lembaga lainnya. Untuk itu PKBI DKI hadir dalam masalah seksual anak usia dini maupun remaja. Agar anak-anak mengetahui apa itu seks bukan dari internet, film, dll. Melainkan mereka mengetahui seks itu dari para ahli dalam bidangnya. Dengan tujuan supaya mereka tidak melakukan halhal yang akan merugikan diri sendiri, orang lain, dan lingkungan sekitar 
karena tidak belajar pendidikan seks sesuai ketentuan yang ada. Dengan mereka mengetahui seks dari internet dan bahkan melihat orang-orang di sekeliling mereka melakukan tindakan seksual, itu akan memicu anak untuk menyalahgunakan informasi yang mereka dapat bukan dari ahlinya.

\section{KESIMPULAN}

Dari data yang peneliti dapatkan terkait peran PKBI DKI di masyarakat, menururt peneliti PKBI DKI memiliki peran yang aktif dalam masalah pendidikan seks. Khususnya dengan masalah-masalah yang dialami remaja, hal tersebut menjadi perhatian khusus PKBI DKI terutama yang terkait dengan masalah kesehatan reproduksi, pelecehan seksual, seks bebas, serta HIV dan AIDS. Jadi dengan program yang dimiliki PKBI DKI ini dapat membuat anak-anak paham dengan arti seksualitas yang sehat. Dengan adanya program dari PKBI DKI juga dapat menghindari anak-anak untuk mengakses hal-hal terkait seks di internet yang dapat membahayakan masa depan mereka. PKBI DKI Jakarta sangat berperan dalam pendidikan seks, selain karena PKBI ini telah terdapat di 33 Provinsi di Indonesia, PKBI juga telah banyak bekerja sama dengan sekolah-sekolah dari sekolah dasar hingga sekolah menengah untuk sosialisasi terkait pendidikan seks. Selain dengan sekolah, beberapa PKBI juga telah bekerja sama dengan puskesmas sekitar dalam pelayanan kesehatan reproduksi remaja.

Dari hasil wawancara, peneliti mendapatkan beberapa informasi terkait pendidikan. Banyak sekali materi pendidikan seks yang diberikan, mulai dari tumbuh kembang anak yang bertujuan agar anak mengetahui perkembangan yang akan terjadi didalam dirinya di usia-usia tertentu. Kesehatan reproduksi juga diajarkan kepada anak agar anak dapat menjaga kesehatan reproduksi supaya tidak terkena penyakit yang dapat membahayakan dan mengganggu masa depannya. PKBI DKI juga mengajarkan tentang pelecehan seksual dan perilaku seksual kepada anak, agara anak tidak melakukan halhal yang dapat merugikan masa depannya dan menjauhkan anak dari tidakan pelecehan seksual.

Dari beberapa informasi dan data lapangan, dapat disimpulkan bahwa media yang dipakai PKBI DKI dalam pendidikan seks bertujuan agar pesan yang disampaikan tidak monoton dan anak tidak bosan dengan pembelajaran pendidikan seks. Banyak sekali media yang digunakan PKBI DKI dalam pendidikan seks tersebut, tidak berbeda jauh dengan materi dakwah pendidikan seks, PKBI DKI juga menggunakan media sesuai dengan usia para peserta. Namun, untuk power point digunakan di semua kalangan, untuk boneka, film animasi, dan puzzle biasanya hanya digunakan untuk anak sekolah dasar.

\section{REFERENSI}

A. Hasjmy, (1884). Dustur Dakwa menurut Al-Qur'an. Jakarta: Bulan Bintang.

Aceh, Aboebakar, Potret Dakwah Muhammad saw dan Para

TARBAWY: Indonesian Journal of Islamic Education - Vol. 4 No. 2 (2017) | 160 
Sababatnya, Solo:

Ramadhani, 1986.

Amin, Samsul Munir, Ilmu Dakwah, Jakarta: Amzah, 2009

Andika, Seks Pra Nikah, Jakarta: Zahra, 2010.

Andriana, Elga, Problema Anak Usia

Dini Berbasis Gender, Yogyakarta:

Kanisius, 2006.

Anshari, Hafi, Pemahaman dan Pengalaman Dakwah, Surabaya: Al-Ihlas, 1993.

Arikunto, Suharsimi, Prosedur Penelitian Suatu Pendekatan Praktik, Jakarta: PT Rineka Cipta, 2006.

Arnold, Thomas W, Sejarah Dakwah Islam (Terjemahan dari The Preaching of Islam), Jakarta: Wijaya, 1981.

Arsip "Buku Putih CMM Periode 2016-2019”

Bachtiar, Wardi, Metodologi Penelitian Ilmu Dakwah, Jakarta: Logos, 1997.

Hana, Yasmin, Ayo Ajarkan Anak Seks, Jakarta: PT Elex Media Komputindo, 2009.

Hathout, Hasan, Pendidikan Seks, Bandung: Remaja Rosdakarya, 1992.

Helmy, Masdar, Dakwah dalam Alam Pembangunan Jilid I, Semarang: CV Toha Putra, 1973.

Lestari, Endang, Peran Orang Tua Dalam Memberikan Pendidikan Seks Sedini Mungkin Di TK Mardisiwi Desa Kedondong Kecamatan Kebonsari Kabupaten Madiun, Jurnal Ilmiah Pendidikan vol. 02 no.02 thn. 2014.
Madani, Yousef, Pendidikan Seks Usia Dini Bagi Anak. Muslim, Jakarta: Zahra Publishing House.

Maharani, Dian, Pentingnya Pendidikan Seks Sejak Dini, Jakarta: Kencana, 2005.

Martin, Sex Slaves, Jakarta: Yayasan Obor Indonesia, 1998.

Moleong, Lexy J, Metodologi Penelitian Kualitatif, Bandung: Remaja Rosdakarya, 2002.

M. Roqib, Pendidikan Seks Pada Anak Usia Dini, Insania vol.13 no.2 thn.2008, h.6.

Muriah, Siti, Metode Dakwah Kontemporer, Yogyakarta: Mitra Pustaka, 2000.

Omar, Toha Yahya, Ilmu Dakwah, Jakarta: Wijaya, 1979.

Sarwono, Sarlito Wirawan, Teori-Teori Psikologi Sosial, Jakarta: Rajawali Pers, 2003.

Sripsiadi, Erwin J, Pendidikan Dasar Seks Untuk Anak, Yogyakarta: Curiosita, 2005.

Subagyo, P. Joko, Metode Penelitian Dalam Teori dan Praktek, Jakarta: Rineka Cipta, 1997.

Subroto, Darwanto Sastro, Televisi Sebagai Media Pendidikan, Yogyakarta: Duta Wacana University Press, 1995.

Sugiyono, Metode Penelitian Kuantitatif, Kualitatif dan R\&D, Bandung: Alfabeta, 2008.

Tasmara, Toto Tasmara, Komunikasi Dakwah, Jakarta: Media Pratama, 1987.

Toto Tasmara, Komunikasi Dakwah, Jakarta: CV Gaya Media Pratama, 1997. 
Ulwan, Abdullah Nashih, Pendidikan

Seks, Bandung: PT Remaja

Rosdakarya, 1996.

Yakub, Ali Musthafa, Sejarah dan

Metode Dakwah Nabi, Jakarta:

Pustaka Firdaus, 1997.

www.cnnindonesia.com

ecpatindonsia.org

http://www.waspada.co.id

Googleweblight.com/?lite_url=http:/

/telaga.org/berita_telaga/pendi

dikan_seks_dalam_keluarga

education-mantap.blogspot.co.id/

2009/12/pendidikan-seks-di-

sekolah

datarental.blogspot.co.id/2015/11/un

sur-unsur-dakwah

TARBAWY: Indonesian Journal of Islamic Education - Vol. 4 No. 2 (2017) $\mid \mathbf{1 6 2}$ 